\title{
Factors Influencing Work Efficiency in China
}

\author{
Wei Wei, Robert J. Taormina* \\ Psychology Department, Faculty of Social Sciences and Humanities, University of Macau, \\ Macau (SAR), China. \\ Email: *Taormina@umac.mo \\ Received November 14 $4^{\text {th }}$, 2011; revised December $18^{\text {th }}$, 2011; accepted December $29^{\text {th }}$, 2011.
}

\begin{abstract}
The preferred methods of conflict handling are largely sociologically prescribed in China, but those methods could reduce efficiency in the workplace. This study examined factors that could influence the efficiency of working people since efficiency is important to the successful operation of organizations. Some relatively unexplored personality variables, i.e., Creativity and Resilience, Esteem from Others, Attribution for Success (to Self), and Attribution for Success (to Others), and some more usual variables, i.e., Conscientiousness, Self-Confidence, and Organizational Socialization (Training, Understanding, Coworker Support, Future Prospects), were tested for their expected positive relationships to three dependent variables, i.e., Work Efficiency, Conflict Handling-Avoidance, and Conflict Handling-Compromising. Questionnaire data from 192 Chinese employees in Mainland China were analyzed to assess these relationships. Correlation results indicated that all variables (except Future Prospects and Attribution to Others) were positively related to Work Efficiency, and most were positively related to both Conflict Handling-Avoidance, and Conflict Handling-Compromising. Results for the relationships of the personality and social variables to conflict handling and work efficiency are discussed in terms of Chinese culture.
\end{abstract}

Keywords: Chinese Culture, Conflict Handling, Compromising, Work Efficiency

\section{Factors Influencing Work Efficiency in China}

Chinese society is known for its dedication to Confucian values, which stress harmony in social relationships as a principal societal objective (Yang, 1995), such that, for example, avoiding conflict in the near-term could maintain harmony over the long-term. At the same time, however, as Lu, Kao, Siu, and Lu (2010) noted regarding conflicts in the workplace, using an avoidance coping strategy might not always be optimal, i.e., "withdrawing from the stressful reality and conceding to fate may give one momentary peace of mind and protect social harmony, but such passive adaptation does not eradicate the stressors” (p. 301). Nonetheless, Kirkbride, Tang, and Westwood (1991), who used paired statements reflecting five conflict handling styles (e.g., competing versus collaborating) found the most chosen options for the Chinese to be compromising and avoiding. While this societal preference for avoiding conflict to maintain harmony is a well-known predilection for the Chinese, what has not been sufficiently examined is whether there are personality factors that could influence one's preferred conflict-handling style, and the extent to which each of the preferred conflicthandling styles is related to the employees' work efficiency.

Employee efficiency is an important concept for human resource management as well as for overall organization performance. Organizations need to be efficient in order to compete and survive in the modern economic environment. The reason for this can be readily understood from the definition of the word "efficiency" which means "to be productive without waste" (e.g., of time or energy), namely, "effective operation as measured by a comparison of production with cost, as in energy, time, and money" (Merriam-Webster, nd). This implies that improving employees' efficiency at work should be very important to the organization's economic performance. According to Taormina and Gao (2009), since efficiency is considered to be a means to achieve organizational goals, high efficiency is desired by management for their organizations to attain high effectiveness.
Given the concern about avoiding conflict in Chinese society, this research also considers personality factors that might be related to how employees handle conflicts at work, since conflict in the workplace could create interpersonal problems, e.g., for work teams, that could interfere with organization efficiency (Liu, Fu, \& Liu, 2009)

Since work efficiency, as a specific measure, was a newly discovered variable (Taormina \& Gao, 2009), there is no existing theory about it. The closest concept is work performance, which is a very general term that could include a number of different components, while work efficiency is a more specific concept. There have been many studies on work performance, and some indicate that good work performance contributes to desired organization outcomes (Maxham, Netemeyer, \& Lichtenstein, 2008). On the other hand, a few papers used a concept named work efficiency, but they examined this variable in terms of specific tasks (e.g., Paul, 1967), without examining personality factors, such as the unique attributes of creativity and resilience, that might contribute to employee work efficiency. Thus, this research also examines personality factors that may be related to work efficiency.

\section{Research Objectives}

The main objectives of this research were to identify personality and organizational factors that could be related to employee work efficiency, as well as to ways that employees handle conflicts at work. In particular, some unique and less studied personality factors, i.e., Creativity, Resilience, Esteem received from Others, Attribution for Success (to Self), and Attribution for Success (to Others), as well as some more standard variables, namely, Conscientiousness, Self-Confidence, and aspects of organizational socialization (Training, Understanding, Coworker Support, Future Prospects), were examined for their possible influence on the dependent measures. Also missing from the literature are studies on the above variables using data from Mainland China. Thus, this study uses data from employees in two cities in southwest and northeast China, i.e., Kunming and Changchun, 
respectively.

To facilitate understanding of the expected relationships among the variables for this study, the dependent variables are described first, followed by the independent variables with their hypothesized relationships to the dependent variables.

\section{Dependent Variables}

Work Efficiency. Taylor (1911) first put forward the concepts of efficiency when he introduced the scientific study of work methods in order to improve worker efficiency. Taylor pioneered a method, now known as the "time-and-motion" study, for determining the best way to reduce time and effort (improve efficiency). Taormina and Gao (2009) indicated that efficiency refers to obtaining the most output from the least amount of input. Accordingly, managers should be concerned with employee work efficiency since high efficiency should lead to lower costs but better products, which would benefit the organization. Consequently, since the specific variable of Work Efficiency has not been sufficiently examined, and the factors contributing to it are not clear, it is necessary to further investigate work efficiency.

Conflict Handling. Barki and Hartwick (2004) defined conflict in the work setting as "a dynamic process that occurs between interdependent parties as they experience negative emotional reactions to perceived disagreements and interference with the attainment of their goals" (p. 216). Conflicts occur everywhere, including in the workplace; and since conflicts disrupt personal relationships, they could disrupt work performance, which requires finding ways to handle them. Blake and Mouton (1964) suggested some methods that people use in conflict situations, and Rahim (1983) developed several measures for handling interpersonal conflict, including avoiding, compromising, and dominating. As this study was conducted in China, where harmonious relationships are a cultural imperative (Yang, 1995), the dominating approach to conflict handling should be rare and, for this reason, was not examined in this study. Thus, only the two styles of Conflict Handling-Avoidance and Conflict Handling-Compromise were investigated.

Conflict Handling-Avoidance. Rahim, Magner, and Shapiro (2000) explained that, when there is conflict, the use of the avoiding style refers to ignoring, taking no action, or withdrawing from the situation; and stated that this style tends to not satisfy the concerns of either party in the conflict.

Conflict Handling-Compromising. Rahim et al. (2000) stated that, for this style, both parties must give up something in order to reach a mutually satisfying decision. Furthermore, a person using the compromising style would give up more than a dominating person, but would address the concern more directly than an avoiding person, thereby splitting the difference with the other party in order to reach a middle ground.

\section{Independent Variables}

Creativity. There has been a growing consensus among creativity researchers regarding the appropriateness of defining creativity in terms of an outcome, such as an idea or product (Amabile, 1988). In particular, Amabile's (1988) definition of creativity is the "production of novel and useful ideas" (126). This makes creativity especially relevant to human resource management, and, consistent with this operationalization, that definition of creativity is adopted for this study.

Although not extensively studied in the human resource literature, some research has been conducted on creativity in the workplace. For example, Rasulzada and Dackert (2009) found that organizational climate and work resources were significantly related to perceived creativity and innovation in organizations. In addition, according to Oldham and Cummings (1996) employees produced the most creative work when they had creativity relevant personal characteristics, e.g., when they were insightful, intelligent, original, inventive, resourceful, and reflective. These characteristics would likely allow such individuals to think of ways to perform their work more easily and effecttively. Therefore,

H(1): The more Creativity employees have, the more Work Efficiency they will have.

With regard to Conflict Handling (Avoidance and Compromise), creative individuals would probably find conflict to be disruptive to their work and, thus, when employees are subjected to some problems with work and personal relationships in an organization, they are inventive enough to find new ways to avoid them. Alternately, if the conflict is unavoidable, they might also be creative enough to think of ways to compromise, but without losing too much in the deal. Therefore,

H(2): The more Creativity employees have, (a) the more Conflict Handling-Avoidance they will use; and (b) the more Conflict Handling-Compromise they will use.

Resilience. Although the concept of resilience has been defined in different ways, the dictionary definition of resilience, i.e., "The act of rebounding or springing back" (Oxford English Dictionary, nd) is used here. Likewise, research on resilience has taken two approaches, namely, one that views resilience as a set of traits (Jacelon, 1997), and the other, from the counseling literature, sees it as a process of receiving support from other people. Here, resilience is viewed as a personal characteristic. Also, one theory of resilience that fits either approach is that by Antonovsky (1987), who sees resilience as a characteristic of people in good health, which allows them to resist threats to their well-being and to spring back in the face of adversity.

With regard to Work Efficiency, the personal-characteristics view would argue that resilient people would not give up when they are faced with difficulties at work, and, instead, would try harder to complete their tasks, which would result in better performance. Thus,

H(3): The more Resilience employees have, the more Work Efficiency they will have.

Regarding Conflict Handling (Avoidance and Compromise), Resilience should also be relevant. The research from counseling, which, at the same time fits the Antonovsky (1987) model, describes resilient individuals as having experienced and survived stressful situations. There is research support for this model, e.g., that individuals who successfully survived stressful situations have personal characteristics that allow them to rebound from the stress to live successful lives (Parker, Cowen, Work, \& Wyman, 1990). Thus, resilient people may be more sensitive to stress, and, since conflict is stressful, they would want to avoid it, if possible, or, if it is unavoidable, to compromise in order to reduce its duration. Hence,

H(4): The more Resilience employees have, (a) the more Conflict Handling-Avoidance they will use; and (b) the more Conflict Handling-Compromise they will use.

Conscientiousness. Conscientiousness is one of the Big Five personality dimensions, which characterizes people as being careful, reliable, hardworking, and organized (Costa \& McCrae, 1985). As such, it is likely to be an attribute that managers would want their employees to possess, and it has been studied extensively in regard to work performance. In particular, Barrick and Mount (1991) conducted a meta-analysis of the Big Five personality dimensions and argued that Conscientiousness 
should be related to job performance because it relates to a person being careful and hardworking, which are characteristics that help one to accomplish their work assignments. They found Conscientiousness to predict all job performance criteria, and concluded that "Individuals who exhibit traits associated with a strong sense of purpose, obligation, and persistence generally perform better than those who do not" (p. 18). Thus, this variable is expected to reveal similar results with Work Efficiency.

H(5): The more Conscientious employees are, the more Work Efficiency they will have.

For Conflict Management (Avoiding and Compromising) and Conscientiousness, relatively little research has been performed, and is thus inconclusive. Antonioni (1998), for example, found no significant correlations between Conscientiousness and the two types of Conflict Handling. When the data were split for student and managers in regression analyses, Conscientiousness could not predict Avoiding for either group, and could not predict Compromising for students, but was a negative predictor for managers, i.e., managers who were less conscientious were more likely to compromise.

That study was conducted in the West, but since this study is for Chinese, a different logical argument is used, i.e., if Conscientiousness is characterized by being careful, then conscientious employees may prefer to avoid conflict; at the same time, however, since conscientious people are also planful, reliable, and responsible, they might also be inclined to compromise in negotiations in order to reach more agreeable solutions to a conflict. Hence,

H(6): The more Conscientiousness employees have, (a) the more Conflict Handling-Avoidance they will use; and (b) the more Conflict Handling-Compromise they will use.

Self-Confidence. Based on Kolb (1999), self-confidence is defined as the degree of perceived probability of success at a task. Some research found that self-confidence was related to past experience and the feedback from past experience (McCarty, 1986). This research, however, views self-confidence as a precursor of Work Efficiency, with the idea that people who are confident of their abilities would be more likely to perform well. In other words, people with high self-confidence would likely think that they are more able to solve problems at work, and thus work more efficiently. This idea has been supported in a study by Hanton and Connaughton (2002), who found that higher levels of self-confidence were associated with higher performance. Thus,

H(7): The more Self-Confidence people have, the more Work Efficiency they will have.

For Conflict Handling, people with high Self-Confidence might believe they can readily solve a conflict and prefer not to argue about it, and thus might avoid conflicts. For compromise, people high on Self-Confidence might be open to using compromise because they would not worry about giving up something in the negotiations since they feel sure that they could rely on themselves if the compromised solution does not work. Therefore,

H(8): The more Self-Confidence people have, (a) the more Conflict Handling-Avoiding, and (b) the more Conflict Handling-Compromising they will use.

Esteem from Others. Esteem is generally defined as the worth or value that is placed on something or someone (Merriam-Webster, nd), and, in psychology, is the positive regard or respect that people have toward themselves or toward other people. Specifically, in Maslow's (1943) hierarchy of needs, esteem, which is a higher-order need, is of two types, namely, selfesteem and esteem received from others. Of the two, there is an abundant literature on self-esteem in the workplace (see Pierce \& Gardner, 2004), but Esteem from Others is a concern of this research because the respect that a person receives from coworkers could affect one's work performance and how that person deals with conflicts at work.

In terms of Work Efficiency, the concept of "face" could play a role. Face generally refers to a person's respectability, or how one is regarded in society. People "have face" when other people respect them, but "lose face" when they are publicly embarrassed, and, in China, social reputation is very important (Hwang, 1987). Thus, if a person already is respected by his or her coworkers, he or she might desire to be more proficient and do excellent work in order to maintain that respect. Therefore,

H(9): The more Esteem from Others employees receive, the more Work Efficiency they will have.

Regarding Conflict Handling, face could also play a role. That is, when conflicts occur, a person who is respected by others might prefer to avoid becoming involved in them as a way of precluding the possibility of losing respect because of disagreements that could result from conflicting views or opinions. In cases where the person who is highly respected by others can not avoid a conflict, once again, in order to maintain the respect they are receiving, the person might be more willing to compromise somewhat so that he or she is not seen as being too inflexible, which could result in losing respect. Thus,

H(10): The more Esteem from Others employees receive, (a) the more Conflict Handling-Avoiding, and (b) the more Conflict Handling-Compromising they will use.

Attribution for Success (to Self and Others). Base on Heider's (1958) causal attribution theory, whereby people make causal inferences about why events occur, e.g., why someone succeeds at a task, due to either one's own efforts (internal) or to environmental (external) causes. In this study, Attribution for Success refers to successes in one's own life and is examined in two dimensions, namely, attribution to oneself for success (i.e., the individual's own efforts led to the success) and attribution to others for success (i.e., helpful efforts of other people led to one's success), which is a recent application of attribution theory (Taormina \& Gao, 2010). People who attribute their successes to their own efforts would likely do so because of their past achievements, e.g., in their jobs, and therefore should perform well at work. Hence, in terms of the dependent measures in this study, people who are high on this factor should perform well and have high Work Efficiency. Regarding attribution to others, Work Efficiency focuses on one's individual performance, so other people might not affect the estimate of one's own effectiveness. Therefore, a relationship is expected only between Attribution to Self and Work Efficiency.

H(11): The more Attribution for Success (to Self) employees engage in, the more Work Efficiency they will have.

With regard to attributions for success and Conflict Handling, people with a high Attribution to Self (i.e., believe their successes are due to their own efforts) would likely have a high sense of personal achievement. Thus, they may be reluctant to involve themselves in conflicts with others and avoid conflicts in preference of searching for solutions that are more suited to their own way of doing things. Also, in the case of conflicts they can not avoid, they might tend to use compromise because they believe that even if they "give up" something, they could rely on themselves in case the compromise should fail.

H(12): The more Attribution for Success (to Self) em- 
ployees engage in, (a) the more Conflict Handling-Avoiding, and (b) the more Conflict Handling-Compromising they use.

For people with a high Attribution to Others (i.e., believe their successes are due to the help received from other people), they would likely avoid conflicts in order to maintain good relationships with others because they might need their help again in future. And when conflicts happen that they can not avoid, they would be more likely to compromise, again for the purpose of keeping good personal relationship in anticipation of obtaining help from others in the future. Therefore,

H(13): The more Attribution for Success (to Others) employees engage in, (a) the more Conflict Handling-Avoiding, and (b) the more Conflict Handling-Compromising they will use.

Organizational Socialization. Organizational Socialization has been defined as "the process by which a person secures relevant job skills, acquires a functional level of organizational understanding, attains supportive social interactions with co-workers, and generally accepts the established ways of a particular organization” (Taormina, 1997, p. 29). It has four domains: Training, Understanding, Coworker Support and Future Prospects. Training refers to the job-related skills organizations provide to employees; Understanding refers to the employees' cognitive comprehension of the way the organization works and the ability to apply that knowledge; Coworker Support refers to both instrumental and emotional sustenance that employees receive from other workers; and Future Prospects refers to employees' expectation about promotion and rewards that the organization makes available.

Previous research showed that these four domains were significantly and positively related to Work Efficiency (Taormina \& Gao, 2009). With regard to Training, Bernardin and Beatty (1984) pointed out that training and development are important parts of the HRM process. Their model of the HRM system demonstrates that through selection, training, development, placement, and motivation, an organization can achieve effectiveness and efficiency among its human resources. Therefore,

H(14): The more highly employees evaluate the Training offered by their organization, the more Work Efficiency they will have.

For Understanding, Reio and Wiswell (2000) studied information seeking as part of workplace learning, which represents increased understanding, and found that it played an important role in job performance. In order to promote work efficiency, an employee needs to learn well and understand how their organizations function, which should help them become more effective and efficient in their work. Therefore,

H(15): The more highly employees evaluate their own Understanding, the more Work Efficiency they will have.

For Coworker Support, positive relationships among coworkers include assistance with tasks (when needed) and moral support, all of which are expected to improve employee work efficiency. Previous research has provided evidence for this idea, i.e., that support among coworkers improves work performance (Lee, 1986) and performance proficiency (Taormina, 2004), and increases productivity (Wolf, 1989); all markers of Work Efficiency. And more recently Coworker Support was also found to be directly related to Work Efficiency (Taormina \& Gao, 2009). Thus, those studies suggest a positive relationship between Coworker Support and Work Efficiency. Therefore,

H(16): The more highly employees evaluate their Coworker Support, the more Work Efficiency they will have.

Future Prospects, according to Taormina (1997), are rewards, benefits, opportunities, and promotions offered by a company that represent types of reinforcement management provides to its employees for doing good work, which should improve the employees work efficiency. Alternately, if good job performance is not rewarded, employee motivation is likely to decline. Empirical support for the positive relationship between Future Prospects and Work Efficiency has been provided by Taormina and Gao (2009). Therefore,

H(17): The more highly employees evaluate their Future Prospects in their companies, the more Work Efficiency they will have.

\section{Method}

\section{Respondents}

The respondents were 192 (62 female, 129 male, 1 no response) Chinese adults aged between 18 and 58 years $(M=36.83, \mathrm{SD}=$ 8.32) working in factories and private companies in Kunming and Changchun China. Highest education levels were: 3 primary school; 21 high school; 53 junior college; 94 bachelor; 18 master or above; 3 no response. For Marital status, 48 were single, 140 married, and 4 other (separated, divorced, widowed, or no response). The average number of children reported was 0.68 $(\mathrm{SD}=0.49)$. Regarding employment, all 192 were employed full-time. Monthly income (in Chinese RMB) was as follows: 3 at <1000; 86 at 1000-2999; 64 at $3000-4999 ; 19$ at $5000-$ 6999; 11 at 7000 - 8999; 4 at 9000 or more, and 5 gave no response.

\section{Measures}

In addition to the demographics, and the 3 main variables (Work Efficiency, Conflict Handling-Avoidance, and Conflict Handling-Compromise), there were 11 independent variables. Unless otherwise noted, all measures asked respondents how well the items described them, using a 5-point Likert scale from 1 (strongly disagree) to 5 (strongly agree).

Demographics. Age and number of children were recorded as given. Other codings were: Gender ( $0=$ female, $1=$ male); Education $(0=$ none, 1 = primary, $2=$ high school, $3=$ junior college; 4 = bachelor, 5 = master or above); Marital status ( 1 = single, 2 = married, 3 = other $)$; Employment $(0=$ none, $1=$ part time, 2 = full-time); Monthly income, in Chinese RMB (1 = 1000, $2=1000-2999,3=3000-4999,4=5000-6999,5=$ 7000 - 8999, $6=9000$ or more).

Work Efficiency. Work Efficiency was measured with an 8-item scale. Four items were derived from Gao and Taormina's (2002) 4-item Work Efficiency scale, which identified some generally accepted performance appraisal criteria across industries in China, e.g., "Able to meet deadlines." To increase the strength of the scale, four more items were added that came from brainstorming by several professionals in the management area, i.e., "Prioritize my tasks effectively", "Complete tasks quickly", "Make efficient use of my time at work", and "Use the most effective methods for doing the work". Respondents were asked to indicate how often these criteria describe their performance, and answered on a 5-point frequency scale, ranging from 1 (almost never) to 5 (almost always).

Conflict Handling Styles. The two Conflict Handling Styles of Avoiding and Compromising were each measured by 5-item scales. All items were from Rahim's (1983) scales for handling interpersonal conflict. The five Avoiding items were from Rahim's (1983) 7-item Avoiding subscale, e.g., "I avoid confronting others". And the five Compromising items were from his com- 
promising subscale, e.g., "I negotiate with others so that a compromise can be reached". Respondents were asked how often they performed the actions described by the statements when they have conflicts with other people, and their answers were recorded on a 5-item scale ranging from 1 (never) to 5 (very often).

Esteem. Esteem Needs were measured using a newly created 12-item scale. All the items were developed from Maslow's $(1943,1971,1987)$ theory of need satisfaction. According to Maslow, Esteem Needs are of two types, Esteem for Self, and Esteem from Others. Only Esteem from Others was assessed with six statements on satisfaction with the respect and recognition the respondent receives from other people, e.g., "The prestige I have in the eyes of other people". Respondents were asked how much they are satisfied with what is described in the statements (items). Answers were on a 5-point Likert scale ranging from 1 (very dissatisfied) to 5 (very satisfied).

Attribution for Success. Two separate, 5-item scales from Taormina and Gao (2010) were used to assess the extent to which the respondents evaluated the successes in their life as being determined by their own efforts, for Attribution-to-Self, or the efforts of other people, for Attribution-to-Others. Sample items included "Principally the result of your own effort" (for Self), and "Mostly the result of help received from others" (for Others). Respondents were asked to what extent they agreed or disagreed that their successes in life were due to each reason (scale item).

Organizational Socialization. Organizational socialization was measured using Taormina’s (2004) Organizational Socialization Inventory, which has four subscales, namely, Training, e.g. "This organization has provided excellent job training for me", Understanding, e.g., "I know very well how to get things done in this organization", Coworker Support, e.g., "My relationships with other workers in this company are very good", and Future Prospects, e.g., "There are many chances for a good career with this organization".

Resilience. This was measured with a 12-item scale. Three items were from Connor and Davidson's (2003) Resilience scale, i.e., "When things look hopeless, I usually give up" [R], "I am able to make it through difficult times", and "Coping with stress strengthens me", and one item was from Lang, Goulet, and Amsel (2003), i.e., "I am easily discouraged by failure" [R]. The remaining items were newly created, i.e., "I do not let things stop me from achieving my goals", "If something bad happens to me, I will bounce back", "If I do not succeed at first, I will surely try again", "I keep on trying even in difficult situations", "The difficulties in my life have made me a stronger person", "I am determined to finish what I start despite obstacles in the way", "I am determined to be a survivor, even in the hardest times", and "I am a person who has great resolve".

Creativity. Creativity was measured with a 10 -item scale. Two of the items were from Simonton's (1986) 12-item Intellectual Brilliance factor of his Presidential Personality adjective checklist, and the adjectives were converted to statements, i.e., "I am an insightful person" and "I am an inventive person". The remaining eight items were newly created, i.e., "I $a$ m $a$ very creative person", "I enjoy coming up with new ideas", "I have a vivid imagination", "I like to create new things", "I enjoy trying different ways of doing things", "I am very good at brainstorming", "I am very original in my thinking", and "I can solve problems that cause other people difficulty".

Conscientiousness. To measure Conscientiousness of the Big Five personality dimensions, its subscale of Perfectionism was assessed. This was a 10-item scale composed of four items from the Perfectionism scale of the HEXACO Personality In- ventory (Lee \& Ashton, 2004), two items from the Abridged Big-Five dimensional Circumplex Model (AB5C; Hofstee, deRaad, \& Goldberg, 1992), one item from the Revised version of the NEO Personality Inventory (NEO-PI-R) (Costa \& McCrae, 1992), and three newly created items, i.e., "Dislike mistakes", "Like things to be in order", and "Am not bothered by mistakes" [R].

Self-Confidence. This was measured by a 10 -item scale. Four items were adapted from Lane, Sewell, Terry, Bartram, and Nesti's (1999) 9-item Self-Confidence Scale of the Competitive State Anxiety Inventory-2 (e.g., "I feel confidence in myself'). Three items were adapted from Kolb’s (1999) 5-item Self-Confidence Scale (e.g., "I have confidence in my own decisions"). Two were adapted items from Hirschfeld et al.'s (1977) 15-item Lack of Social Self-Confidence Scale (e.g., "I am very confident about my own judgments"), and one item was adapted from Day and Hamblin's (1964) 10-item Self-Esteem and Self-Confidence Scale (e.g., "I usually feel that my opinions are inferior"). All the items were slightly reworded to focus more on introspective self-confidence rather than a specific social context.

\section{Procedure and Ethical Considerations}

As the objective of this study was to assess Chinese people on their Work Efficiency and Conflict Handling, a purposive sample of employees was used, i.e., data were collected from employed people in factories and companies in Kunming and Changchun, China. With permission from management, questionnaires were brought to the locations on work days and personally handed to the employees, who were asked to complete them during their break times. The questionnaire took about 10 to 15 minutes to complete, and, when finished, were handed back to the researcher on site. Together, 192 completed questionnaires were returned out of 230 that were handed out, yielding a response rate of $83.48 \%$.

Ethical guidelines of the American Psychological Association were followed in the study. Informed consent of participants was obtained verbally and through the cover page of the questionnaire, which introduced the survey and gave the researcher's contact information. Potential participants were informed that their participation was entirely voluntary, and that they could stop responding at any time. They were also assured that their identities, personal information, and responses would never be revealed to anyone, and that their data would be used only in combined statistical form so that they could never be personally identified.

\section{Results}

\section{Demographic Differences}

Although no hypotheses were made regarding the demographics, t-tests and ANOVAs were performed to assess their differences on the dependent variables of Work Efficiency, Conflict Handling-Avoiding, and Conflict Handling-Compromising.

For Gender, there was only one significant difference, with Females $(\mathrm{M}=3.54$, $\mathrm{SD}=0.73)$ higher than Males $(\mathrm{M}=3.24$, SD $=0.87$ ) on Conflict Handling-Avoiding, $\mathrm{t}(189)=2.37, p<0.05$.

For having Children, there was also only one difference, with the No Children group $(\mathrm{M}=3.70, \mathrm{SD}=0.61)$ higher than the Having Children group $(\mathrm{M}=3.45$, SD $=0.73$ ) on Conflict Handling-Compromising, $\mathrm{t}(182)=2.35, \mathrm{p}<0.05$. There were no other significant differences among any other demographics on any of the other dependent variables. 


\section{Variable Correlations and Test for Common Method Bias}

Correlations were computed for all the variables to assess their relationships and to test the hypotheses. Overall, all hypotheses were supported except four, i.e., not significantly related were: $\mathrm{H}(2 \mathrm{a})$ Creativity and Conflict Handling-Avoiding; $\mathrm{H}(8 \mathrm{a})$ Self-Confidence and Conflict Handling-Avoiding; $\mathrm{H}(13 a)$ Attribution for Success to Others and Conflict Handling-Avoiding; and H(17) Future Prospects and Work Efficiency.

To test for possible multicollinearity of the data, commonmethod bias was assessed by factor analyzing all the variables together, using the maximum-likelihood approach with a forced, one-factor solution (see Harman, 1960). The resultant Chisquare value is then divided by the degrees of freedom to assess model fit, whereby a ratio of less than 2.00:1 would indicate common- method bias (i.e., a single factor). For this study, the ratio was 5.63:1, suggesting that common-method bias was not a concern.

All of the correlations among the main variables and the dependent variables, as well as the means, standard deviations, and Cronbach Alpha reliabilities of the variables, are shown in Table 1.

\section{Regressions}

Three regressions were run to determine the extent to which any of the independent variables could statistically predict the dependent variables. For Work Efficiency, 36\% of the variance was explained, $\mathrm{F}(3,168)=31.66, p<0.001$. Three variables entered the regression equation (all positively), with Attribution for Success to Self explaining $27 \%$ of the variance, Self-Confidence explaining $7 \%$, and Conscientiousness explaining $2 \%$.

For Conflict Handling-Avoiding, 8\% of the variance was ex- plained, $\mathrm{F}(2169)=7.48, p<0.001$. This time, two variables entered the regression, with Attribution for Success to Self explaining 6\%, and Gender explaining 2\% (with females higher than males on this variable).

For Conflict Handling-Compromising, 26\% of the variance was explained, $\mathrm{F}(3168)=20.15, p<0.001$. Three variables entered this regression (all positively), with Attribution for Success to Self explaining $21 \%$ of the variance, Conscientiousness explaining 3\%, and Attribution for Success to Others explaining 2\%.

\section{Discussion}

This research examined personality and organizational factors for their relation to employee Work Efficiency and how employees handle work conflicts. While there were a few demographic differences, this discussion centers on the main personality variables and their relation to the dependent measures, particularly from the perspective of Chinese culture.

\section{Personality, Work Efficiency, and Chinese Culture}

Among the variables selected for study, Self-Confidence and Conscientiousness have been commonly used in human factors research, while others, especially Creativity, have been used less frequently. In particular, although certain personality variables, namely, Creativity, Resilience, and Esteem from Others, have not been extensively studied before, these factors were found to have significant and positive correlations with Work Efficiency. Furthermore, in regard to Chinese culture, even though Creativity and Resilience are often thought to be characteristic of western, "individualistic" culture, both of these variables had relatively high mean scores on their measurement scales. This suggests that these personality characteristics are not unique to any particular culture, and implies that managers in Chinese culture could begin to look at these characteristics among their employees.

Table 1.

Means, standard deviations, Cronbach alpha reliabilities, and correlations of the main variables $(N=192)$.

\begin{tabular}{|c|c|c|c|c|c|c|}
\hline & Mean & SD & Work Efficiency & $\begin{array}{l}\text { Conflict Handling } \\
\text { Avoid }\end{array}$ & $\begin{array}{l}\text { Conflict Handling } \\
\text { Compromise }\end{array}$ & $\begin{array}{c}\text { Alpha } \\
\text { Reliabilities }\end{array}$ \\
\hline Work Efficiency & 3.95 & 0.61 & - & - & - & 0.93 \\
\hline Conflict-Handling Avoid & 3.33 & 0.83 & $0.14+$ & - & - & 0.83 \\
\hline Conflict-Handling Compromise & 3.53 & 0.69 & $0.35^{* * * *}$ & $0.47^{* *}$ & - & 0.84 \\
\hline Creativity & 3.63 & 0.60 & $0.40 * * * *$ & 0.09 & $0.26 * * * *$ & 0.90 \\
\hline Resilience & 3.64 & 0.55 & $0.35 * * * *$ & $0.15^{*}$ & $0.27 * * * *$ & 0.86 \\
\hline Conscientiousness & 3.51 & 0.42 & $0.37 * * * *$ & $0.17^{*}$ & $0.30 * * * *$ & 0.69 \\
\hline Self-Confidence & 3.68 & 0.45 & $0.44 * * * *$ & 0.07 & $0.19 * *$ & 0.84 \\
\hline Esteem from Others & 3.53 & 0.58 & $0.33 * * * *$ & $0.22 * * *$ & $0.29 * * * *$ & 0.88 \\
\hline Attribution to Self & 3.58 & 0.58 & $0.50 * * * *$ & $0.24 * *$ & $0.44 * * * *$ & 0.74 \\
\hline Attribution to Others & 2.88 & 0.69 & 0.01 & 0.13 & $0.16^{*}$ & 0.79 \\
\hline Training & 3.46 & 0.76 & $0.14+$ & $0.14+$ & 0.11 & 0.88 \\
\hline Understanding & 3.69 & 0.70 & $0.31^{* * * *}$ & $0.19 * *$ & $0.25 * * * *$ & 0.86 \\
\hline Coworker Support & 3.67 & 0.64 & $0.20 * *$ & 0.09 & 0.12 & 0.81 \\
\hline Future Prospects & 3.09 & 0.83 & 0.05 & 0.02 & 0.03 & 0.82 \\
\hline
\end{tabular}

$+p<0.10 ; * p<0.05 ; * * p<0.01 ; * * * p<0.005 ; * * * * p<0.001$. 
In traditional Chinese thinking, self-promotion is antithetical to the culture such that creative employees do not come forward, which makes it is difficult to identify them. That is, the hierarchically structured culture, which is reflected strongly in Chinese organizations, leads the employees to wait for instructions from their superiors. At the same time, the employee with creative ideas would be inhibited from promoting those ideas for fear of being seen as self-aggrandizing, and, consequently, possibly being rejected by his or her coworkers. Likewise, he or she might fear being seen by superiors in a negative light, e.g., since the superior is expected to be the leader, the superior might think the creative employee is imposing on his or her leadership and thereby causing him or her to "lose face" by presenting new ideas that everyone expects the leader to put forward; and/or the leader might regard the creative employee as a bothersome "show-off" who does not fit in with the group.

The positive correlations between creativity and work efficiency, along with the limiting organizational circumstances for creative people, imply that managers could try to find ways to foster creativity among employees. For example, research has suggested that creativity can be taught (Williams, 2001). At the same time, managers also need to find ways that allow creative employees to propose their creative ideas, e.g., by creating channels (perhaps written ones) through which to put forward those ideas, without suffering negative consequences either from their peers or from their superiors.

\section{Personality, Conflict Handling, and Chinese Culture}

Regarding Conflict Handling, first, it is well known that social harmony is paramount in Chinese culture (Yang, 1995). Thus, among the many ways that conflict could be handled, the two most suitable in Chinese culture are to avoid them or to compromise in order to resolve them amicably (Kirkbride et al., 1991). The results found some personality variables positively related to conflict avoidance (although the correlations were not especially powerful). This might be because avoiding conflict is practiced by almost everyone throughout Chinese society, which means that, for Chinese people, no particular personality characteristic is especially associated with avoiding conflicts.

For Conflict Handling-Compromising, there were much stronger positive correlations; and the difference with Avoiding is as follows: The act of avoiding conflict is very easy to do, i.e., when conflicts occur, one only needs to stay away (or walk away) from them. Compromising, however, requires a person to have some special skills to do this successfully. For example, to be good at compromise, one must be able to negotiate, know what to ask for, what to give up, how much to give up, and when to give up. The remarkable finding in the results was that many of the variables selected for this study were so highly, significantly, and positively related to compromising.

These correlations may be strong for reasons that can be found in Chinese culture. Because of the importance of maintaining social harmony, and since interpersonal conflicts are inevitable in life, it becomes necessary to find ways to compromise that are agreeable to both parties. In looking at the results of the regression analyses for predicting the use of compromise, three variables, namely, Conscientiousness, Self-Confidence, and Attribution to Self for one's success in life, account for all the explained variance, and this is a strong effect $\left(\mathrm{R}^{2}=0.26 ; f^{2}=\right.$ 0.35; for computing effect size, see Cohen, 1992). The correlations and the variables that predicted compromise may be determined by Chinese culture.

In particular, traditional Chinese culture teaches one to be conscientious in various ways, such as through obedience, work- ing hard, being trustworthy, and maintaining harmony with others (see Chinese Culture Connection, 1987). Thus, conscientiousness seems to be advocated in Chinese culture, and its characteristics of being careful and responsible make persons with those quailties more effective at reaching mutually agreeable compromises.

Regarding Self-Confidence and Chinese culture, there are (anecdotal) examples of Chinese Deans in Chinese universities, e.g., one gained self-confidence from successfully attaining a professsorship in an overseas university, and, when appointed as Dean in a Chinese university, refused to compromise, using his authority as a power to win in any disagreement. But this refusal to compromise led them to be disliked by all his subordinates. On the other hand, when a person abides by Chinese values, he or she would fit better into, and be more likely to succeed in, Chinese society, which includes interacting successfully with other people. With such successful experiences, one becomes more assured about how to reach agreements, including "giving up" something in the process of making compromises in order to maintain harmony with others.

For Chinese culture and Attribution for Success to Self, which was the third variable that predicted compromise, again, one's past successes and personal achievements in life that are gained through abiding by Chinese values likely lead to greater self assurance and self reliance, which allows one to be less afraid to make compromises.

\section{Overall Summary}

This study assessed how the Chinese societal preference for harmony may impact two preferred conflict-handling styles in relation to work efficiency; and found a stronger positive correlation between handling conflicts by using compromise (versus using avoidance) and work efficiency. Also, Creativity, Resilience, Conscientiousness, Self-Confidence, Esteem from Others, Attributions for Success to Self, and most of the dimensions of organizational socialization were also positively and significantly related to Work Efficiency. Taken together, the results seem to imply that the Work Efficiency of Chinese employees could be improved in many ways, including through organizational socialization and the use of compromise in handling conflicts. Finally, Chinese culture appeared to be very useful in explaining how some social and personality characteristics can be influential in predicting such important outcomes as work efficiency and handling conflicts.

\section{References}

Amabile, T. M. (1988). A model of creativity and innovation in organizations. In B. M. Staw and L. L. Cummings (Eds.), Research in Organizational Behavior (pp. 123-167). Greenwich, CT: JAI Press.

Antonioni, D. (1998). Relationship between the Big Five personality factors and conflict management styles. International Journal of Conflict Management, 9, 336-355. doi:10.1108/eb022814

Antonovsky, A. (1987). Unravelling the mystery of health: How people manage stress and stay well. San Francisco: Jossey-Bass.

Barki, H., \& Hartwick, J. (2004). Conceptualizing the construct of interpersonal conflict. International Journal of Conflict Management, 15, 216-244. doi:10.1108/eb022913

Barrick, M. R., \& Mount, M. K. (1991). The Big Five personality dimensions and job performance: A meta-analysis. Personnel Psychology, 44, 1-26. doi:10.1111/j.1744-6570.1991.tb00688.x

Blake, R. R., \& Moutin, J. S. (1964). The managerial grid. Houston, TX: Gulf.

Bernardin, H. J., \& Beatty, R. W. (1984). Performance appraisal: Assessing human behavior at work. Boston: Kent.

Chinese Culture Connection (1987). Chinese values and the search for 
culture-free dimensions of culture. Journal of Cross-Cultural Psychology, 18, 143-164. doi:10.1177/0022002187018002002

Cohen, J. (1992). A power primer. Psychological Bulletin, 112, 155159. doi:10.1037/0033-2909.112.1.155

Connor, K. M., \& Davidson, J. R. T. (2003). Development of a new resilience scale: The Connor-Davidson Resilience Scale (CD-RISC). Depression and Anxiety, 18, 76-82. doi:10.1002/da.10113

Costa, P. T., \& McCrae, R. R. (1985). The NEO personality inventory manual. Odessa, FL: Psychological Assessment Resources.

Costa, P. T., \& McCrae, R. R. (1992). NEO-PI-R professional inventory manual. Odessa, FL: Psychological Assessment Resources.

Day, R. C., \& Hamblin, R. L. (1964). Some effects of close and punitive styles of supervision. The American Journal of Sociology, 69, 499-510. doi:10.1086/223653

Gao, J. H. \& Taormina, R. J. (2002). Performance appraisal in Zhuhai and Macao. Proceedings of the 7th International Human Resource Management Conference, Limerick: University of Limerick.

Hanton, S., \& Connaughton, D. (2002). Perceived control of anxiety and its relationship to self-confidence and performance. Research Quarterly for Exercise and Sport, 73, 87-97.

Heider, F. (1958). The psychology of interpersonal relations. New York: Wiley. doi:10.1037/10628-000

Hirschfeld, R. M. A., Klerman, G. L., Gough, H. G., Barrett, J., Korchin, S. J., \& Chodoff, P. (1977). A measure of interpersonal dependency. Journal of Personality Assessment, 41, 610-618. doi:10.1207/s15327752jpa4106 6

Hofstee, W. K., de Raad, B., \& Goldberg, L. R. (1992). Integration of the Big Five and circumplex approaches to trait structure. Journal of Personality and Social Psychology, 63, 146-163. doi:10.1037/0022-3514.63.1.146

Hwang, K. K. (1987). Face and favor: The Chinese power game. American Journal of Sociology, 92, 944-974. doi:10.1086/228588

Jacelon, C. S. (1997). The trait and process of resilience. Journal of Advanced Nursing, 25, 123-129. doi:10.1046/j.1365-2648.1997.1997025123.x

Kirkbride, P. S., Tang, S. F., \& Westwood, R. I. (1991). Chinese conflict preferences and negotiating behavior: Cultural and psychological influences. Organization Studies, 12, 365-386. doi:10.1177/017084069101200302

Kolb, J. A. (1999). The effect of gender role, attitude toward leadership and self-confidence on leader emergence: Implications for leadership development. Human Resource Development Quarterly, 10, 305320. doi:10.1002/hrdq.3920100403

Lane, A. M., Sewell, D. F., Terry, P. C., Bartram, D., \& Nesti, M. S. (1999). Confirmatory factor analysis of the Competitive State Anxiety Inventory-2. Journal of Sports Science, 17, 505-512. doi:10.1080/026404199365812

Lang, A., Goulet, C., \& Amsel, R. (2003). Lang and Goulet hardiness scale: Development and testing on bereaved parents following the death of their fetus/infant. Death Studies, 27, 851-880. doi:10.1080/716100345

Lee, D. M. S. (1986) Academic achievement, task characteristics, and first job performance of young engineers. IEEE Transactions on Engineering Management, EM-33, 127-133.

Lee, K., \& Ashton, M. C. (2004). Psychometric properties of the HEXACO personality inventory. Multivariate Behavioral Research, 39, 329-358. doi:10.1207/s15327906mbr3902_8

Liu, J., Fu, P., \& Liu, S. (2009). Conflicts in top management teams and team/firm outcomes: The moderating effects of conflict-handling approaches. International Journal of Conflict Management, 20, 228250. doi:10.1108/10444060910974867

Lu, L., Kao, S. F., Siu, O. L., \& Lu, C. Q. (2010). Work stressors, Chinese coping strategies, and job performance in Greater China. International Journal of Psychology, 45, 294-302.

doi:10.1080/00207591003682027

Maslow, A. H. (1943). A theory of human motivation. Psychological Review, 50, 370-396. doi:10.1037/h0054346

Maslow, A. H. (1971). The farther reaches of human nature. Oxford:
Viking.

Maslow, A. H. (1987). Motivation and personality (3rd ed.). Boston: Addison-Wesley.

Maxham, J. G., Netemeyer, R. G., \& Lichtenstein, D. R. (2008). The retail value chain: Linking employee perceptions to employee performance, customer evaluations, and store performance. Marketing Science, 27, 147-167. doi:10.1287/mksc.1070.0282

McCarty, P. A. (1986). Effects of feedback on the self-confidence of men and women. Academy of Management Journal, 29, 840-847. doi: $10.2307 / 255950$

Merriam-Webster Dictionary (nd). http://www.merriam-webster.com/dictionary/

Oldham G. R., \& Cummings, A. (1996). Employee creativity: Personal and contextual factors at work. Academy of Management Journal, 39, 607-634. doi:10.2307/256657

Oxford English Dictionary (nd).

http://www.oed.com/view/Entry/163619

Parker, G., Cowen, E., Work, W., \& Wyman, P. (1990). Test correlates of stress resilience among urban school children. The Journal of Primary Prevention, 11, 19-35. doi:10.1007/BF01324859

Paul, R. J. (1967). Increasing the work efficiency of the service employee. Journal of Small Business Management, 5, 9-13.

Pierce, J. L., \& Gardner, D. G. (2004). Self-esteem within the work and organizational context: A review of the organization-based self-esteem literature. Journal of Management, 30, 591-622. doi:10.1016/j.jm.2003.10.001

Rahim, M. A. (1983). A measure of styles of handling interpersonal conflict. Academy of Management Journal, 26, 368-376. doi: $10.2307 / 255985$

Rahim, M. A., Magner, N. R., \& Shapiro, D. L. (2000). Do justice perceptions influence styles of handling conflict with supervisors? What justice perceptions, precisely? International Journal of Conflict Management, 11, 9-31. doi:10.1108/eb022833

Rasulzada, F., \& Dackert, I. (2009). Organizational creativity and innovation in relation to psychological well-being and organizational factors. Creativity Research Journal, 21, 191-198. doi:10.1080/10400410902855283

Reio, T. G., \& Wiswell, A. (2000). Field investigation of the relationship among adult curiosity, workplace learning, and job performance. Human Resource Development Quarterly, 11, 5-30. doi:10.1002/1532-1096(200021)11:1<5::AID-HRDQ2>3.0.CO;2-A

Simonton, D. K. (1986). Presidential personality: Biographical use of the Gough Adjective Check List. Journal of Personality and Social Psychology, 51, 149-160. doi:10.1037/0022-3514.51.1.149

Taormina, R. J. (1997). Organizational Socialization: A multidomain, continuous process model. International Journal of Selection and Assessment, 5, 29-47. doi:10.1111/1468-2389.00043

Taormina, R. J. (2004). Convergent validation of two measures of organizational socialization. International Journal of Human Resource Management, 15, 76-94. doi:10.1080/0958519032000157357

Taormina, R. J. \& Gao, J. H. (2009). Identifying acceptable performance appraisal criteria: An international perspective. Asia Pacific Journal of Human Resources, 47, 102-125. doi:10.1177/1038411108099292

Taormina, R. J. \& Gao, J. H. (2010). A research model for guanxi behavior: Antecedents, measures, and outcomes of Chinese social networking. Social Science Research, 39, 1195-1212. doi:10.1016/j.ssresearch.2010.07.003

Taylor, F. W. (1911). The principles of scientific management. New York: Harper Bros.

Williams, S. (2001). Increasing employees' creativity by training their managers. Industrial and Commercial Training, 33, 63-68. doi:10.1108/00197850110385642

Wolf, J. R. (1989). Human resource management. Psychiatric Annals, 19, 432-434.

Yang, K. S. (1995). Chinese social orientation: An integrative analysis. In T. Y. Lin, W. S. Tseng and E. K. Yeh (Eds.), Chinese Societies and Mental Health (pp. 19-39). Hong Kong: Oxford University Press. 